\title{
LAS CONCEPCIONES SOBRE EL DESARROLLO REGIONAL EN LAS POLÍTICAS PÚBLICAS DEL SUR-SURESTE MEXICANO Y EN LOS PROYECTOS AUTOGESTIVOS DE LAS COMUNIDADES LOCALES: UNA CONTRASTACIÓN A LA LUZ DE LAS INCONSISTENCIAS DEL PLAN PUEBLA-PANAMÁ \\ CONCEPTIONS ON THE REGIONAL DEVELOPMENT IN THE SOUTHERN-SOUTHEAST MEXICAN PUBLIC POLICIES AND IN THE SELF-MANAGED PROJECTS OF THE LOCAL COMMUNITIES: A CONTRASTING IN VIEW OF THE WEAKNESSES OF THE PLAN PUEBLA-PANAMA
}

\author{
Isaac Enríquez Pérez \\ Universidad Nacional Autónoma de México \\ isaacep@unam.mx
}

Recibido: 18/06/2011

Aceptado: 23/12/2011

\begin{abstract}
Resumen
El presente artículo se orienta a explicar e interpretar el sentido de la acción social ejercida por actores y agentes socioeconómicos y políticos que intervienen en el proceso de planeación, tomando como punto de partida el reconocimiento y comprensión de las concepciones sobre el desarrollo regional esbozadas por ellos en sus comunicados, directrices y documentos estratégicos que emplean para incidir en una macrorregión como el Sur-Sureste mexicano en el marco de lo que se denominó como Plan Puebla-Panamá. Se plantea la tesis de que el desarrollo regional no es un proceso espontáneo, sino que es un proceso dirigido y gestionado mediante políticas públicas en las cuales convergen múltiples actores y agentes que hacen valer sus prioridades e intereses en los procesos de construcción de mercados y redistribución de la riqueza. Se trata pues de interpretar y contrastar la naturaleza, los alcan-
\end{abstract}


ces y limitaciones de las concepciones sobre el desarrollo regional expresadas por los gobiernos locales y las fuerzas sociales opositoras en el contexto de políticas públicas transfronterizas promovidas en espacios de reserva.

Palabras clave: Concepciones sobre el desarrollo regional; políticas públicas; planeación del desarrollo; acción colectiva y movimientos sociales; proyectos alternativos de desarrollo; Plan Puebla-Panamá.

\begin{abstract}
This paper is oriented to explain and interpret the meanings of social action performed by actors and agents socio-economic and political involved in the process planning, taking as its starting point the recognition and comprehension of conceptions of regional development outlined in their communications, guidelines and strategic documents that they use to impact in a macro-region as the South-Southeast of Mexico under what is termed as the Plan Puebla-Panama. The thesis is that regional development is not a spontaneous process, but a process designed and managed through public policies in which multiple actors and agents converge, who assert their priorities and interests in the process of building markets and redistribution of wealth. The question is to interpret and compare the nature, scope and limitations of the regional development conceptions expressed by local governments and oppositional social forces in the context of cross-border policies promoted in spaces of reserve.
\end{abstract}

Keywords: Conceptions of regional development; public policy; development planning; social movements; alternative projects of development; Plan Puebla-Panama.

\title{
INTRODUCCIÓN
}

El desarrollo regional no consiste en un proceso espontáneo desenvuelto en vacíos institucionales y socioculturales, ni menos aún se expresa de manera equilibrada y armónica en el territorio. Es mas bien un proceso de toma de decisiones -concertadas o impuestas- orientadas a la estructuración de espacios locales que posibiliten el despliegue del proceso productivo, las interacciones responsables con el medio ambiente, la edificación de infraestructura básica y el mejoramiento de la calidad de vida; es también un proceso contradictorio y polarizado cuyas manifestaciones territoriales evidencian las disparidades y diferenciaciones regionales. Sin que ello implique una postura determinista, es importante reconocer que los desequilibrios y las desigualdades territoriales son inevitables, y que solo mediante y desde los entramados institucionales de una sociedad es posible generar cambios o contener los efectos negativos del proceso de desarrollo y de los condicionantes físico/ambientales.

El desarrollo regional está profundamente vinculado con la estructuración de los mercados y con la dinámica que adquieren éstos en el marco de interacciones asimétricas entre los actores y agentes socioeconómicos involucrados. Con esto pretendemos argumentar que la concepción o concepciones 
que se promuevan sobre el desarrollo regional estarán en función de la manera en que se construyen los mercados, así como de la correlación de fuerzas políticas, económicas y sociales que interfieren en la toma de decisiones propias de la definición de los problemas públicos y de la agenda de gobierno expresados en las políticas públicas.

Son precisamente las políticas públicas los principales instrumentos de planeación e intervención que poseen las instituciones gubernamentales. Con ellas, es posible delinear y modelar la organización y dinámica que se desean para una sociedad en el marco de la interacción con los grupos de presión, los intereses creados y las fuerzas sociales opositoras (véase diagrama 1).

Reconocido lo anterior, cabe plantearse preguntas como las siguientes: ¿Cuáles fueron las concepciones sobre el desarrollo regional esbozadas en las políticas públicas locales en el marco del diseño y adopción del Plan PueblaPanamá? ¿Cuáles son las especificidades que caracterizan a estos instrumentos de intervención estatal en el marco de la reconfiguración de los espacios locales/regionales condicionados por los procesos de globalización? ¿Cómo se configura la acción social de los actores y agentes socioeconómicos y políticos que inciden en la planeación del desarrollo regional? ¿Cuáles son los supuestos teórico/epistemológicos que están detrás de las concepciones que se adoptan en las políticas públicas en torno al desarrollo regional? ¿Cuáles son los factores que inciden en las inconsistencias y el fracaso de las estrategias de desarrollo regional en México? Tras esbozar estas interrogantes, cabe destacar que el presente documento tiene como objetivo principal el identificar e interpretar la lógica y el sentido de las concepciones implícitas en las estrategias de desarrollo regional diseñadas en México, tomando en cuenta las facetas de la acción social desplegadas por los distintos actores socioeconómicos y políticos que intervienen en el proceso de planeación durante un periodo inédito en el cual el aparato de Estado mexicano pretende adoptar políticas públicas de corte transnacional. Lo anterior supone asumir que el objetivo de la presente investigación consiste en delinear la naturaleza de las políticas públicas en los espacios locales, así como de la correlación de fuerzas que inciden en la estructuración de los procesos de desarrollo.

Es de destacar que en el estado del conocimiento sobre el tema no abundan los estudios que enfatizan el análisis e interpretación de las políticas públicas locales; predominan más bien grandes trazos analíticos y empíricos sobre las contradicciones e inconsistencias de las políticas regionales que no necesariamente abordan la naturaleza y estructuración de las concepciones sobre el desarrollo regional, así como los actores y agentes socioeconómicos y políticos que inciden en ello. 
Considerando lo anterior, en un primer apartado se esboza un breve análisis de la importancia de los espacios locales en la estructuración del proceso de desarrollo; se continúa con una caracterización de las condiciones históricas propias del Sur-Sureste mexicano, en tanto macrorregión seleccionada como referente empírico; en un tercer apartado se revisan las concepciones sobre el desarrollo regional difundidas por los gobiernos locales dentro del ámbito espacial seleccionado; se analizan también las estrategias específicas para el desarrollo regional arraigadas en las políticas públicas locales, de tal manera que se estudia la convergencia de dichas estrategias con las propias del Plan Puebla-Panamá en tanto política pública transnacional que involucra a varias entidades federativas mexicanas; con la finalidad de acercarnos a los actores y agentes que diseñan proyectos autogestivos de desarrollo y que disputan el control, apropiación y gestión del territorio, se aborda también el proceso de configuración de la agenda pública y la incidencia de ello en las decisiones relacionadas con el desarrollo regional; y se finaliza con la interpretación de la acción colectiva desplegada por actores y agentes locales que -con base en sus propias concepciones sobre el desarrollo- diseñan proyectos locales autogestivos para el desarrollo endógeno que no necesariamente se corresponden con las políticas públicas locales analizadas, sino que evidencian sus contradicciones y limitaciones.

Cabe agregar que la tesis que estuvo presente constantemente en nuestra investigación es la siguiente: las concepciones sobre el desarrollo regional que se encuentran detrás de la planeación de este proceso, si bien presentan perfiles y características que responden a los intereses y pretensiones de los actores y agentes hegemónicos de la sociedad, también responden a los proyectos y perspectivas alternativos de los movimientos sociales y las fuerzas sociales opositoras; de ahí que se asuma una perspectiva integral para identificar y analizar el sentido de la acción social de esos diferentes actores y agentes que intervienen en la apropiación del territorio y la configuración y gestión de los espacios locales.

\section{LA RELEVANCIA DE LA DIMENSIÓN LOCAL EN LA PLANEACIÓN DEL DESARROLLO ANTE LA INTENSIFICACIÓN DE LOS PROCESOS DE GLOBALIZACIÓN}

Si asumimos que la globalización significa una intensificación de las relaciones sociales que no reconocen fronteras geográficas ni temporales en tanto el mundo se estructura como un todo en lo económico, político, comunicacional, geopolítico y cultural, es necesario reconocer que ante la integración global del capitalismo derivada de ello y la dinámica orgánica y funcional que este modo de producción adquiere a escala planetaria y en tiempo real, los territorios y espacios locales asumen una relevancia inédita incluso más allá de los agregados nacionales. 
Es en los espacios locales donde adquiere forma, se concreta y potencializa el proceso de desarrollo. En el marco de los sistemas internacionales de producción integrada, las escalas locales participan de manera determinante en el proceso de acumulación del capital en tanto nichos que pueden reunir condiciones propicias para la atracción y establecimiento de inversiones productivas. Desde el ámbito local, resulta posible compensar los desequilibrios y desigualdades sociales que trae consigo la imperfecta integración y expansión global de los mercados; detonar y hacer viables las innovaciones institucionales y tecnológicas que propicien la formación de economías de aglomeración y de entramados comunitarios basados en relaciones de confianza, asociatividad y reciprocidad que se traduzcan en capital social necesario para el impulso de proyectos de desarrollo endógeno que contengan y abatan la pobreza y la marginación.

En lo local, los factores y circunstancias endógenas y exógenas se entretejen constituyendo una constelación de retos y oportunidades que pueden plasmarse en la generación de ventajas competitivas que permitan un posicionamiento satisfactorio de la región en los mercados que rebasan sus fronteras. Como los productos finales son resultado de combinaciones internacionales de insumos, las redes empresariales globales que se estructuran en torno a ello apuntalan una nueva división técnica del trabajo que privilegia la fragmentación y transferencia territorial del proceso productivo y su realización en unidades descentralizadas orientadas a agregar alto valor. Dichos procesos, colocan a los espacios locales, en especial a aquellos que gozan de ventajas comparativas y competitivas, en posibilidades de recibir inversiones privadas -inversión extranjera directa en el caso de países como México- y de detonar procesos de crecimiento económico que se traduzcan en un aumento del empleo formal, y en la transferencia de tecnología y know how tanto organizacional como relativo al proceso productivo.

Lo local es también un ámbito propicio para la expresión, mucho más acentuada, de los problemas y desigualdades sociales y territoriales, pues es allí donde se plasman y palpan de manera contundente la polarización y contradicción del mismo proceso de desarrollo y la planeación que de él se realiza. Las demandas sociales que no se resuelven en el nivel nacional de gobierno -tras la intensa participación social- adquieren un mayor vigor en el nivel local en el marco de la relativa descentralización del sector público que experimentan países como México.

En suma, en los espacios locales es posible contener los efectos sociales y económicos derivados de la expansión global del capitalismo, así como asimilar y fortalecer, mediante una mayor productividad y competitividad, las oportunidades que dicha expansión ofrece. 


\section{EL SUR-SURESTE MEXICANO Y SUS CONDICIONES SOCIOHISTÓRICAS}

Históricamente, el desarrollo regional en México se caracteriza por ser un proceso desequilibrado, distorsionado y carente de armonía; resultado de políticas públicas y acciones gubernamentales que privilegiaron el crecimiento de los sectores económicos por encima de consideraciones territoriales y que desembocaron en una centralización y concentración de las actividades económicas y la distribución poblacional. Gran parte de las políticas públicas diseñadas con propósitos de detonar procesos de desarrollo regional se caracterizaron por la improvisación, la débil o nula integración como prioridad en la política económica nacional (Delgadillo, Torres-Torres y Gasca, 2001) y por la escasa articulación integral entre ellas, constituyéndose mas bien en instrumentos inspiradores de acciones gubernamentales fragmentadas y dispersas que son truncadas durante cada transición sexenal. Como resultado de ello y de la estructura focalizada y atemporal de la inversión sectorial, los mercados regionales no se consolidaron como sustento de un desarrollo endógeno más competitivo y como puentes para la intensificación de las relaciones interregionales; mas bien, las disparidades tendieron a profundizarse con la estrategia orientada a la apertura irrestricta de la economía, la cual fortaleció a la regiones más consolidadas.

La macrorregión Sur-Sureste es la expresión más acabada de la polarización que impulsó este largo proceso histórico. Con actividades agropecuarias ligadas al autoconsumo y la subsistencia, escaso establecimiento de inversión extranjera directa, infinidad de actividades productivas y de servicios que no agregan alto valor, un modelo económico que agotó al turismo tradicional como motor del crecimiento, y débiles entramados institucionales, el Sur-Sureste se caracteriza por las mayores desigualdades sociales y los más altos grados de marginación que se expresan en las tensiones que generaron inestabilidad sociopolítica e ingobernabilidad.

Es posible argumentar que en el marco del desarrollo regional desequilibrado, asimétrico, desarticulado y desarticulador que prevaleció históricamente, una macrorregión como la Sur-Sureste fungió básicamente como un sustrato físico/ambiental propicio para la extracción/explotación de recursos naturales. Durante los últimos años, en el marco del proceso de planeación, a las regiones en general y al Sur-Sureste en particular se les concibe como ámbitos para la atracción de inversiones, la generación de ventajas comparativas y competitivas, la inserción en los mercados internacionales, y para la implementación de políticas sociales focalizadas y compensatorias. 


\section{LAS CONCEPCIONES SOBRE EL DESARROLLO REGIONAL PREVALECIENTES EN LAS POLÍTICAS PÚBLICAS LOCALES DEL SUR-SURESTE}

Como reconocemos que el desarrollo regional no es un proceso espontáneo, sino que más bien es un proceso que responde a la concertación entre variados actores y agentes políticos y socioeconómicos y a la concepción que éstos exponen sobre el mismo, entonces la planeación adquiere un papel relevante en las estrategias que pretenden incidir en la dirección y gestión de las actividades económicas en el territorio. Por un lado, la planeación expresa la convergencia en torno a cierta manera de pensar -teórica o políticamente- la estructuración y modelación de una sociedad; y, por otro, plasma las estrategias que el sector público adoptará para intervenir y fomentar el desarrollo. Así pues, las políticas públicas son la

\section{DIAGRAMA N. ${ }^{\circ} 1$}

Configuración de las concepciones sobre el desarrollo regional: relación orgánica entre los factores exógenos y los espacios locales

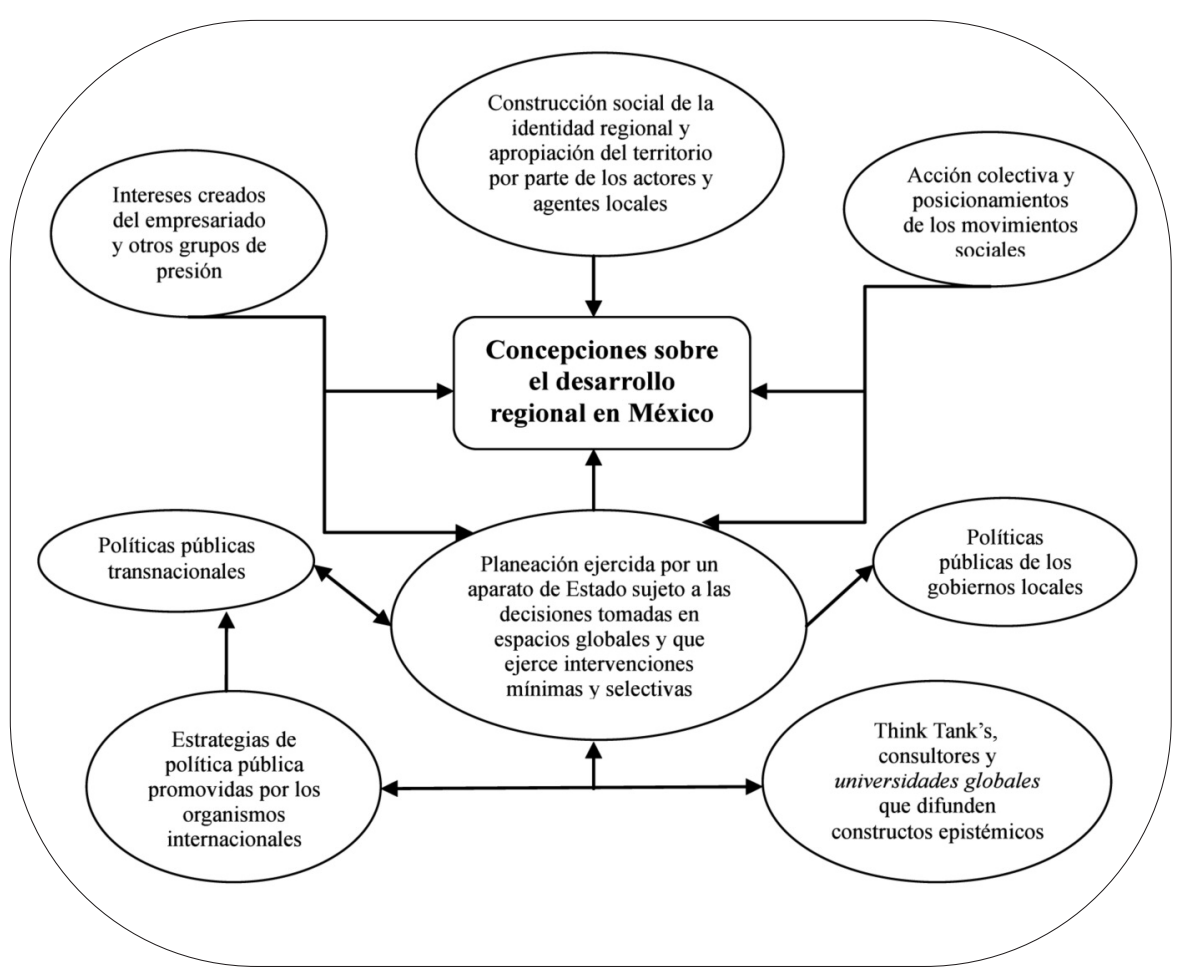

Elaboración propia 
síntesis de la conciliación que emprenden -en el marco de un determinado contexto nacional e internacional y de la construcción histórica de la identidad regional- los actores gubernamentales con los actores socioeconómicos y demás grupos de presión y fuerzas sociales opositoras (véase diagrama 1), de las concepciones que predominan sobre la manera en que se construyen los mercados y se fomenta el proceso de desarrollo, y los objetivos y estrategias que se establecen para esto último. Más aún, en el diseño de las políticas públicas y en la configuración de las concepciones sobre el desarrollo que en ellas predomina, inciden agentes externos como los organismos internacionales -estrategias como el Plan Puebla-Panamá fueron promovidas desde entidades como el BID y la CEPAL-, los consultores que colaboran con éstos y con los gobiernos nacionales, así como el debate académico suscitado dentro de universidades influyentes en torno a los estudios sobre el desarrollo, la planeación y la gestión pública.

Dentro de las políticas públicas diseñadas e implementadas -desde que se anunció el Plan Puebla-Panamá- en las entidades federativas del Sur-Sureste mexicano predominan variadas concepciones sobre el desarrollo regional. Dichas concepciones, en su mayoría, se corresponden con las esbozadas en los planes y programas diseñados por el gobierno federal, y se inspiran también en planteamientos sobre lo local expresados en documentos estratégicos de organismos internacionales que promueven la armonización y estandarización de políticas públicas.

Es importante destacar que todo concepto enmarcado en alguna formulación teórica más amplia relativa al proceso de desarrollo tiene, explícita o implícitamente, propuestas o estrategias de política pública. Es más, dichos conceptos, muchas veces difundidos por organismos internacionales y apropiados por las políticas públicas de alcance nacional, expresan la forma como se piensa el ejercicio de las intervenciones del sector público en el proceso de desarrollo y las estrategias que se adopten para ello.

En las políticas públicas locales revisadas se observa que el concepto de desarrollo sustentable es el más extendido y compartido entre ellas. Esto se relaciona con el cuestionamiento de las estrategias que privilegiaron la función extractiva y de explotación de los recursos naturales en las regiones del SurSureste. La democratización de los sistemas políticos locales aparece como otra de las prioridades gubernamentales, y más aún si se considera la tensión sociopolítica y la crisis de representatividad vivida en algunas entidades federativas. En materia de política social, la formación y expansión de capacidades, en el marco de un nuevo asistencialismo focalizado y compensatorio, se presenta como una prioridad que privilegia la atención a los grupos sociales en condiciones de pobreza extrema. La recurrencia al concepto de equidad de género y 


\section{CUADRO N. ${ }^{\circ} 1$}

\section{Constructos teóricos que sustentan las concepciones sobre el desarrollo regional en las políticas públicas locales}

\begin{tabular}{l|l}
\hline Conceptos básicos & Argumento principal \\
\hline Teoría general de sistemas & En el ordenamiento territorial esta teoría logra plasmar
\end{tabular}

(Gobierno del estado de sus postulados mediante la consideración y consolida-

Campeche, 2004) ción del paradigma del desarrollo sustentable.

Planeación estratégica

Enfatizar la participación de distintos actores y agentes sociales en la planeación del proceso de desarrollo. Estas incursiones, que por naturaleza tendrían que ser activas, se orientan a la definición de los problemas públicos y al diseño e implementación de las políticas públicas.

\begin{tabular}{l|l}
\hline Desarrollo sustentable & Plantear las interconexiones equilibradas entre la calidad
\end{tabular}
del medio ambiente y el manejo adecuado de los recursos naturales, el crecimiento económico y el bienestar social. El desarrollo sustentable se relaciona con el uso racional de los recursos naturales y con el respeto a sus ciclos de regeneración, el cuidado del entorno físico/ambiental, la preservación de la capacidad productiva de éste, y con la transformación de los hábitos de consumo, de tal manera que no se vea comprometido o amenazado al momento de transmitirse a las futuras generaciones. La transmisión generacional de los acervos de capital -tanto natural como económico y humano- tendría que ser igual o mayor al disponible por la población que la emprende.

Equidad de género

La equidad de género es la concepción que precisa las relaciones entre ambos sexos, reconociendo las especificidades culturales de los problemas suscitados en la interacción entre el hombre y la mujer.

Desarrollo humano (Gobierno del estado de Chiapas, 2001; Gobierno del Estado de Veracruz, 1999; Gobierno del Estado de Tabasco, 2002; y Gobierno del Estado de Yucatán, 2001)

Cambio estructural de la economía (Gobierno del Estado de Oaxaca, 1999)
El desarrollo humano es un proceso orientado a la ampliación, más allá del ingreso monetario, de las opciones y oportunidades que posibiliten el mejoramiento de la calidad de vida. Dichas opciones y oportunidades se generan mediante la formación, expansión y aprovechamiento de las capacidades.

Transformar la estructura económica para facilitar la atracción de inversión productiva y la generación de confianza entre los agentes económicos para aumentar la formación de capital. La industrialización, la apertu ra de las economías locales y la construcción de infraes tructura orientada a ello se consideran fundamentales para el aumento de la productividad. 


\begin{tabular}{l|l}
\hline Conceptos básicos & Argumento principal \\
\hline $\begin{array}{l}\text { Capital social (Gobierno } \\
\text { del Estado de Yucatán, } \\
\text { 2001). }\end{array}$ & $\begin{array}{l}\text { Enfatizar la capacidad de autogestión de las comunida- } \\
\text { des con base en las relaciones de confianza, reciprocidad } \\
\text { y asociatividad con la finalidad de emprender proyectos } \\
\text { que propicien su desarrollo. }\end{array}$ \\
\hline Democratización. & $\begin{array}{l}\text { Emprender reformas electorales que permitan el plura- } \\
\text { lismo político, el respeto al voto y la procuración de la } \\
\text { gobernabilidad democrática. }\end{array}$ \\
\hline $\begin{array}{l}\text { Modernización } \\
\text { administrativa }\end{array}$ & $\begin{array}{l}\text { Hacer eficiente, eficaz y menos costosa la gestión públi- } \\
\text { ca desconcentrando y delegando funciones y responsabi- } \\
\text { lidades a escalas menores de gobierno. Ello con la finali- } \\
\text { dad de ofrecer servicios públicos de calidad y en las can- } \\
\text { tidades necesarias, erradicando prácticas de corrupción. }\end{array}$ \\
\hline $\begin{array}{l}\text { Derechos de propiedad } \\
\text { (Gobierno del estado de } \\
\text { Campeche, 2004; Gobierno } \\
\text { del Estado de Quintana } \\
\text { Roo, 1999). }\end{array}$ & $\begin{array}{l}\text { Crear entramados institucionales que brinden seguridad } \\
\text { jurídica a la tenencia de propiedad, así como viabilidad } \\
\text { a las transacciones económicas. }\end{array}$ \\
\hline $\begin{array}{l}\text { Ventajas comparativas } \\
\text { de las regiones }\end{array}$ & $\begin{array}{l}\text { Especializarse en la actividad económica que goce de una } \\
\text { mayor productividad y competitividad o en el impulso } \\
\text { al recurso o factor productivo que sea más abundantes. }\end{array}$ \\
\hline
\end{tabular}

de capital social responde a la histórica exclusión social padecida por la mujer, y a la omisión hecha respecto a las circunstancias culturales de las comunidades y su potencial para autogestionar el desarrollo y combatir la pobreza.

Conceptos como el relacionado con la modernización administrativa apuntan a resarcir las debilidades e ineficiencias de las intervenciones del sector público y a generar confianza en sus funciones y organizaciones. En este sentido, instituciones como la procuración e impartición de justicia y la garantía de los derechos de propiedad para proteger la tenencia de bienes y su participación en las transacciones de compraventa -la individualización y escrituración de las parcelas que componían los ejidos es muestra de ello- y para disminuir los costos de transacción se asumen como parte de las reformas estructurales inspiradas en el enfoque del nuevo institucionalismo económico. Dichos costos de transacción tradicionalmente se incrementaron con la falta de sistemas de transporte, información y de asistencia técnica adecuados, así como con el exceso de trámites burocráticos para invertir. La certidumbre jurídica y la procuración de la seguridad pública se presentan como condiciones para el fortalecimiento de las economías locales y para el aumento de su competitividad en el plano internacional. 
Estos debates teóricos sobre el desarrollo forman parte de las concepciones esbozadas en las políticas públicas en torno a éste proceso. En el papel, son complemento de las estrategias federales en materia de política económica y que se fundamentan en la estabilización, desregulación, privatización y apertura de la economía nacional. A pesar de su naturaleza inconexa en la implementación de las políticas públicas y en las acciones gubernamentales que inspiran, los documentos oficiales postulan una integración sistémica de las estrategias deflacionarias con los conceptos y presupuestos presentados en el cuadro anterior.

En las políticas públicas locales revisadas, el gobierno estatal se asume como convocante y gestor de la atracción y establecimiento de inversión privada, sobre todo extranjera, en sus respectivas entidades -lo cual implicaría revisar las regulaciones y las normas para atraer y arraigar inversiones y empleo, e incluso en algunos casos, acelerar las privatizaciones o concesiones del sector público federal (Gobierno del Estado de Veracruz, 1999)-, en especial aquella canalizada a la micro, pequeña y mediana empresa, a las actividades agroindustriales, a la industria maquiladora -en ramas como el ensamble de aparatos electrodomésticos y la fabricación de autopartes, actividades a fomentar en las entidades que no las atraen y explotan suficientemente- y al desarrollo turístico en modalidades como el ecoturismo. Se argumenta que con la atracción de la inversión directa se posibilitará la incorporación de nuevas tecnologías y la apertura a nuevos canales de comercialización. La construcción de infraestructura básica -en especial comunicaciones viales para lograr la integración territorial-, productiva y de servicios, y de parques o corredores industriales, así como la modernización tecnológica son presentadas como las líneas de acción necesarias para generar condiciones propicias que estimulen los procesos productivos y de comercialización. Las acciones en materia de educación y capacitación para el trabajo se consideran necesarias para generar capacidades humanas y aumentar la competitividad del mercado laboral y responder así a las exigencias que imponen los procesos de calidad en las empresas. El mismo combate a la pobreza extrema y el abatimiento de los rezagos en materia de infraestructura social se postulan como acciones indispensables para contrarrestar la inestabilidad sociopolítica en vastas zonas del Sur-Sureste y para la generación y mantenimiento de la gobernabilidad que brinde confianza a los inversionistas. Sin embargo, a pesar de la apertura económica intensificada en la última década, el Sur-Sureste recibe los flujos mas bajos de inversión extranjera directa (datos aportado en Bustamante Lemus, et. al., 2004).

La construcción de nuevos marcos institucionales para la atracción y establecimiento de la inversión se vincula también con la creación de condiciones que estimulen un sector empresarial suficientemente diversificado dotado de instrumentos para la formación y desarrollo de una nueva cultura empresarial 
apta para el aprovechamiento de las oportunidades que ofrece la economía internacional. Gobiernos locales como el de Yucatán asumen un papel activo de su entidad en materia de comercio exterior proponiendo la promoción de encadenamientos productivos y competitivos para una mayor incorporación de empresas a la actividad exportadora, adicionar mayor valor agregado a los bienes y servicios exportables, y acceder a los mercados internacionales.

En la consolidación de algunas actividades productivas y la diversificación de las economías estatales, la nueva racionalidad de las políticas públicas está marcada por la orientación hacia los mercados internacionales. Se propone la transformación de la estructura productiva para estimular e incrementar la participación de la industria manufacturera en las economías estatales -en entidades como Guerrero (Gobierno del estado de Guerrero, 1999), cuya economía gira fundamentalmente alrededor del turismo se propone la diversificación económica con miras a una mejor inserción en el ámbito internacional-. Son precisamente las maquiladoras y las industrias competitivas las que se conciben como las principales fuentes de empleo. El fomento a la llamada economía popular y al autoempleo artesanal y microempresarial son contemplados como elementos que pueden contribuir a la formalización de los mercados laborales. Se sostiene que el fomento de agrupamientos industriales y empresariales en ramas industriales, con ventajas comparativas, incentivarán el incremento de la productividad y la calidad (Gobierno del Estado de Yucatán, 2001).

Se apuesta en las políticas públicas a consolidar y revalorar las actividades turísticas en aras de estimular un dinamismo que incentive y remolque la producción industrial -en ramas como la construcción, alimentos y bebidas procesadas, y la microindustria-, la producción artesanal y la comercialización de productos de madera y pesqueros. Se argumenta que con el turismo y su vinculación con las actividades agropecuarias e industriales será posible diversificar las estructuras económicas de las entidades, desarrollar regiones rurales, atraer inversiones recreativas, aumentar el ingreso de divisas, promover la microndustria y la artesanía local, difundir la diversidad cultural y natural, e incentivar el surgimiento de nuevos polos de desarrollo turístico y de corredores turísticos en torno a los destinos tradicionales. De ello se desprende la importancia que se le otorga a la construcción de nueva infraestructura carretera y aeroportuaria o al mejoramiento de la existente. Así pues, el turismo es propuesto como un detonador del crecimiento económico.

Explícitamente, se hace referencia a la necesidad de aprovechar y estimular las ventajas comparativas y competitivas y la posición geográfica que guardan algunos estados en la geografía nacional e internacional, de tal forma que las entidades se conviertan en sólidas receptoras de inversiones tanto públicas como privadas y en centros económicos competitivos. Esto se engloba en una función 
promotora y de fomento de los gobiernos locales que se sustenta en una estrategia de incentivos al empresariado y de intervención pública excepcional y complementaria en el proceso económico. En este sentido, la desregulación de la actividad económica en materia de proteccionismo, trámites y controles se asume como prioritaria para disminuir los costos de transacción.

En suma, se trata en materia de crecimiento económico de propiciar un aumento de la eficiencia general de la economía estatal y superar las limitaciones derivadas de una insuficiente infraestructura, de la calidad de los insumos y de los mercados regionales distorsionados.

Respecto al desarrollo regional, en la mayoría de las políticas públicas locales del Sur-Sureste se le concibe como un proceso reducido a la demarcación político/administrativa de cada estado, y en los casos en que se asume como una empresa relacionada con el resto de las entidades federativas vecinas no se logran estructurar las estrategias y las líneas de acción necesarias. Esto es, sólo llega a esbozarse una planeación destinada al ámbito microrregional, o bien, a la regionalización que comprende más de dos municipios del estado. A lo sumo, al desarrollo regional se le relaciona con la coordinación que se emprenda entre los gobiernos locales y el gobierno federal y con la formulación de instrumentos de planeación regional que propongan políticas de actuación sectorial y que consoliden las interrelaciones regionales. Sólo en materia de turismo se busca una promoción más allá de las fronteras estatales, e incluso la coordinación entre entidades para la construcción de infraestructura propia para esas actividades.

El gobierno del estado de Campeche (2004) sugiere una estrategia que apunte a impulsar acciones para consumar procesos de integración regional mediante la promoción de la activa participación de los estados de la península en el diseño de estrategias de aplicación regional; la formulación de instrumentos de colaboración para la atención de problemáticas interestatales; el planteamiento de una mayor y mejor distribución de recursos y programas por parte de la federación al estado; y la participación en la coordinación y adopción de programas federales en la entidad e impulsar sus beneficios. Respecto a la planeación del desarrollo regional y al manejo y cuidado de los corredores ecológicos, otros gobiernos como el de Chiapas (2001) propone asociaciones municipales, no solo al interior de una misma entidad sino también entre municipios de varios estados. En el ámbito de los corredores ecológicos, este mismo gobierno se suma a la iniciativa del Corredor Biológico Mesoamericano, con la finalidad de unir las áreas naturales de Chiapas con las zonas silvestres que se encuentran en Tabasco, Campeche y Quintana Roo, y con las que se localizan en Guatemala y Belice.

Reconociendo que el crecimiento de las economía local también está en función de las definiciones nacionales sobre la planeación del desarrollo de la macrorregión Sur-Sureste, algunos gobiernos locales como los de Chiapas, 
Tabasco y Yucatán, que asumieron el poder después del año 2000, expresan en sus documentos oficiales referencias explícitas al Plan Puebla-Panamá; incluso en Tabasco se contemplan acciones concretas en materia de infraestructura orientadas a éste proyecto transfronterizo. Se sugiere que el Plan Puebla-Panamá se constituya en una palanca para que el Sur-Sureste mexicano acceda a un estadio de desarrollo similar al del resto del país; para ello, será importante la homogeneización de criterios y prioridades entre las estrategias del Plan Puebla Panamá y las políticas públicas locales, con la finalidad de encontrar puntos de confluencia y coordinación entre los gobiernos federal y estatales (Gobierno del estado de Chiapas, 2001). Es más, se señala en algunos casos que la inversión pública del gobierno local será orientada a partir de las estrategias del Plan Puebla-Panamá.

Como tradicionalmente al desarrollo regional se le acotó a las características físico/ambientales del territorio, en algunas políticas públicas locales se aspira a construir nuevas estructuras regionales que reconozcan los perfiles sociodemográficos y culturales de las distintas unidades territoriales, de tal manera que sea posible señalar las especificidades por microrregiones, y poder así diseñar políticas sectoriales que atiendan, valorando su vocación productiva y sus potencialidades, los problemas públicos que enfrenta cada una.

\section{LAS ESTRATEGIAS PARA EL DESARROLLO REGIONAL EXPRESADAS EN LAS POLÍTICAS PÚBLICAS LOCALES}

Las políticas públicas locales, en materia de desarrollo regional enfrentan -en el Sur-Sureste mexicano- las siguientes problemáticas: relaciones asimétricas de las entidades federativas con el gobierno federal; dispersión poblacional en el medio rural, lo cual dificulta la provisión de servicios básicos; las herencias históricas que reducen a la región a una función meramente de extracción/ explotación de los recursos naturales, y que en el caso del petróleo y la energía eléctrica no se vincularon del todo con la estructura económica de los estados; actividades productivas agropecuarias que continúan siendo de autoconsumo y subsistencia, acompañándose ello de proporciones importantes de la población económicamente activa que habita en el medio rural y labora en una economía agrícola de autosubsistencia, baja productividad y nula rentabilidad; débil desarrollo industrial que en su mayoría privilegia la industria extractiva; desarrollo agroindustrial limitado; mercados internos débiles como consecuencia del bajo consumo local; escasa integración de las economías regionales y dependencia de ellas respecto al mercado del centro del país para la comercialización de bienes y servicios; inexistencia de una estructura regional que articulase la actividad económica del campo con la de las ciudades; ausen- 
cia de una apropiada planeación regional y municipal; inadecuadas divisiones municipales en estados como Chiapas y Oaxaca; concentración de las empresas exportadoras en el centro y norte del país; estrategias de desarrollo unisectoriales, y por tanto, poco diversificadas; la adopción de un modelo de desarrollo fincado en la construcción de polos de desarrollo, principalmente turísticos, que no generaron efectos multiplicadores de inversión sobre otras regiones y sectores de menor desarrollo; planeación caracterizada por la desarticulación entre la economía rural y urbana, en el contexto de mercados regionales distorsionados; pobreza extrema y desigualdad social; en entidades como Puebla, un débil encadenamiento productivo entre la grande y la mediana industria, con el resto de la economía local; la baja integración de la infraestructura en comunicaciones, que mantiene atomizados a los mercados; la expulsión de mano de obra; la ausencia de cadenas productivas integradoras que dificulta la obtención de mejores precios en la producción local; la persistencia de tecnologías de producción rudimentarias y cultivos con escaso valor en el mercado; el escaso aprovechamiento económico de las fronteras que se comparten con otros países; desarticulación de las cadenas productivas tradicionales; en el caso de Yucatán, explotación e industrialización de una materia prima -el henequén-; la baja capacitación laboral y débil cultura empresarial, entre muchos otros.

Frente a esto, las políticas públicas locales proponen concepciones y estrategias sobre el desarrollo regional que podemos categorizar de la siguiente forma:

El desarrollo regional entendido como reordenamiento territorial, equilibrada distribución poblacional y fortalecimiento de las ciudades medias, relacionado con las líneas de acción que apuntan a contrarrestar el aislamiento y dispersión de los asentamientos humanos y la concentración y excesivo crecimiento de las grandes ciudades, a reorientar el patrón de distribución poblacional y a procurar su crecimiento ordenado, de tal manera que sean agrupados en núcleos rurales dotados de infraestructura básica y servicios públicos o en ciudades medias que sean consolidadas con la definición de un sistema integrado y jerarquizado de las mismas y que a partir de sus especificidades se conviertan en polos de desarrollo microrregional que propicien dinámicas integradoras en sus territorios de influencia. La planeación sectorial y el redespliegue territorial de la economía hacia las ciudades medias estratégicas, se sugiere acompañarla del impulso a la construcción y fortalecimiento de la infraestructura, el equipamiento y los servicios, de tal manera que los asentamientos humanos se ubiquen ordenadamente y se dinamicen las actividades socioeconómicas con efectos multiplicadores en la región. Ante la estructura demográ- 
fica de concentración/dispersión, se instrumentaría desde esta perspectiva un modelo de desconcentración concentrada con estructura policéntrica que convierta a las ciudades medias en ejes detonadores de los polos de desarrollo regional para la atracción de las actividades económicas integrados, mediante la infraestructura, a sus respectivas áreas de influencia, a la totalidad de la entidad y a los ámbitos nacional e internacional.

El fortalecimiento de los municipios como unidades político/administrativas mas inmediatas al desarrollo regional, esto es, el municipio adquiere una relevancia inédita en la solución de las problemáticas socioeconómicas, por lo que se propone la coordinación y colaboración entre los gobiernos municipal y estatal para la implementación de las políticas públicas de alcance regional, el aprovechamiento y habilitación de sus capacidades en los ámbitos de la planeación, la gestión y operación de políticas públicas, impulsándose como unidad territorial básica para el diseño de nuevas regionalizaciones, el impulso de proyectos orientados al desarrollo socioeconómico y para motivar, en el marco del federalismo fiscal, la equilibrada asignación regional del gasto público y la programación de su impacto.

Las regiones como receptoras de politicas sociales focalizadas y compensatorias de la desigualdad social, es una concepción que enfatiza la atención prioritaria a microrregiones -en tanto espacios inmediatos de acción- que padecen la pobreza extrema y la marginación con la finalidad de generar entre sus habitantes, mediante la focalización territorial de los beneficios, las capacidades básicas para remontar dichas condiciones adversas.

El ordenamiento ecológico territorial como condición necesaria para el desarrollo regional, permite, desde la perspectiva del desarrollo sustentable, la preservación, el manejo y aprovechamiento racional del patrimonio natural, enfatizando el manejo integral de las cuencas hidrológicas (Gobierno del Estado de Chiapas, 2001; Gobierno de Oaxaca, 1998).

La edificación, fortalecimiento y mantenimiento de la infraestructura básica y productiva común a varias regiones -en especial, la relativa a energéticos, transporte multimodal, ejes carreteros y vías de comunicación aérea-, se proponen con la finalidad de fomentar la integración regional y como una posibilidad para acceder a los mercados regionales del país y del exterior -en especial a los centroamericanos. La construcción de parques y corredores industriales, aprovechando las ventajas comparativas de las regiones, se postulan como acciones relevantes para la gestión y atracción de inversión privada y para la integración industrial a nivel regional.

La construcción y fortalecimiento de mercados locales como premisa para la integración regional partiendo de la identificación y estímulo de las vocacio- 
nes y potencialidades económico/productivas de las microrregiones para procurar el eslabonamiento vertical y horizontal que propicie la diversificación productiva y la especialización regional; así como el incremento del valor agregado de las cadenas productivas, mediante la promoción de corredores urbano/industriales, urbano/agroindustriales y urbano/comerciales generadores de empleos (Gobierno del estado de Puebla, 1999) y del establecimiento de clusters con altos estándares de calidad en su producción y que permitan la inserción en la economía internacional, en aras de impulsar los mercados regionales de productos y de trabajo y la formación de polos de desarrollo comercial para el intercambio regional que estimule a las ciudades medias y pequeñas, para la integración entre los mercados estatales y el nacional, y para la promoción de las exportaciones. Los factores endógenos y las potencialidades locales adquieren una relevancia inédita para la distribución desconcentrada de las actividades económicas en los territorios.

El turismo como ventaja comparativa para el desarrollo regional, en tanto estrategia pretende elevar la calidad de los servicios turísticos a niveles competitivos internacionalmente e impulsar polos turísticos regionales como instrumentos detonadores del crecimiento. La convocatoria y concertación con el empresariado dedicado al turismo resulta importante para la atracción de inversiones canalizadas a las regiones que cuentan con potencialidades locales.

La integración del sistema de comunidades indígenas a las economías regional, estatal y nacional es una estrategia que, a partir de la reivindicación e impulso de lo rural, se propone en rubros como la representatividad de estas poblaciones ante el sector público; el respeto a sus derechos humanos y a sus manifestaciones culturales; así como el aprovechamiento de sus habilidades en el manejo y preservación de los recursos naturales.

Los espacios fronterizos como zonas para el desarrollo regional, al ser privilegiados por entidades como Chiapas y Quintana Roo que apuestan por la coordinación y cooperación con los gobiernos centroamericanos, pretenden el aprovechamiento de las ventajas estratégicas que se gestan en estas regiones mediante la construcción de infraestructura y el establecimiento de incentivos fiscales y crediticios, asumiendo que la vecindad con Centroamérica puede convertirse en un eje basado en infraestructura industrial y de servicios para la creación de nuevos mercados, la integración comercial y la cooperación científico/tecnológica en el marco del Plan Puebla-Panamá y de tratados de libre comercio como el del llamado Triángulo del Norte y los firmados con Costa Rica y Nicaragua (Gobierno del estado de Chiapas, 2001; Gobierno del estado de Tabasco, 2002; Gobierno del estado de Yucatán, 2001). 


\section{LA CONVERGENCIA DE LAS POLÍTICAS PÚBLICAS LOCALES CON LAS ESTRATEGIAS DEL PLAN PUEBLA-PANAMÁ}

Entre los principales objetivos estratégicos del Plan Puebla-Panamá destacaron: elevar el desarrollo humano y social de la población; emprender cambios profundos en la estructura productiva de la macrorregión, aprovechar las vocaciones y las ventajas comparativas; gestionar, a través de la promoción empresarial, inversiones productivas con la finalidad de aumentar el empleo; manejar los recursos naturales con criterios de sustentabilidad; concertar políticas públicas conjuntas entre la región Sur-Sureste y los países centroamericanos; la modernización y fortalecimiento de los entramados institucionales locales; y la ampliación de la base tecnológica (Presidencia de la República, 2001). Se argumentó que la ventajosa inserción de la macrorregión mesoamericana en la economía internacional dependerá del mejoramiento de su competitividad, entendiendo por ésta el aumento del bienestar social, el manejo racional de los recursos naturales, la inversión eficiente en infraestructura de transportes y comunicaciones, el impulso de la vocación exportadora de la pequeña y mediana empresa, y el mejoramiento del entorno económico y regulativo (BCIE-BIDCEPAL, 2001).

El Plan Puebla-Panamá -en tanto política pública transnacional- incorporó varios proyectos regionales y otros emanados de los mismos países centroamericanos y de los acuerdos comerciales firmados con ellos. Entre estos proyectos destacan los relativos al Corredor Biológico Mesoamericano, al corredor transístmico en la zona de Tehuantepec, al Programa Nacional de Atención a Regiones Prioritarias, al Programa de Desarrollo para 250 Microrregiones, al proyecto de corredor turístico Mundo Maya, a la Agenda para la Competitividad y el Desarrollo Sostenible de Centroamérica hacia el Siglo XXI, y a los proyectos derivados del Grupo Consultivo Regional para la Transformación y Modernización de Centroamérica (Gasca y Torres-Torres, 2003).

Como estrategia, el Plan Puebla-Panamá se estructuró con las llamadas Iniciativas Mesoamericanas que pretenden promover la integración económica y la relación entre los gobiernos y la sociedad civil. Las Iniciativas Mesoamericanas abarcan temas como el desarrollo sustentable; el desarrollo humano para la reducción de la pobreza; la prevención y mitigación de desastres naturales; la promoción del turismo ecológico, cultural e histórico, destacando la complementariedad, las economías de escala y los encadenamientos productivos de esta actividad económica; la facilitación del intercambio comercial mediante la reducción de los costos de transacción y el impulso a la capacidad exportadora de la pequeña y mediana empresa; la integración 
vial para facilitar el desplazamiento de personas y mercancías y reducir así los costos de transporte; la unificación e interconexión energética para aumentar las inversiones en el sector y reducir el precio de la electricidad; y la integración de los servicios de telecomunicaciones. De entre todos estos rubros que en total se proyectó que absorberían 4,017.7 millones de dólares, es el relativo a la infraestructura vial el que recibe el $82.2 \%$ de la inversión estimada, siguiéndole la interconexión energética con el $11 \%$.

Las políticas públicas locales dedicaron un interés especial y un gasto público considerable en materia de construcción, mantenimiento y modernización de infraestructura relativa a las comunicaciones y transportes. Al menos los gobiernos que asumieron el poder después del año 2000 -Chiapas, Tabasco, Yucatán, y Campeche-, en sus documentos oficiales se esboza una vocación explícita y decidida para corresponderse y complementarse con el Plan Puebla-Panamá. Los gobiernos de las otras entidades federativas que ocuparon el poder desde 1998, aunque si bien no existía este proyecto transterritorial, sí hacen referencia a la importancia de algunos de los rubros expresados por las Iniciativas Mesoamericanas, e incluso, algunos de sus gobernadores realizaron visitas a Centroamérica con la finalidad de abrir oportunidades de negocios.

Donde se expresa de manera más acentuada la convergencia entre ambos niveles de políticas públicas es en documentos oficiales complementarios al Plan Puebla-Panamá como el Plan de Desarrollo Integral para la Región SurSureste de México y el Programa Marcha Hacia el Sur. En el primero de ellos, acordado entre el gobierno federal y los poderes ejecutivos locales, se señala la importancia de diseñar políticas públicas integrales para el Sur-Sureste mexicano; la coordinación de acciones entre los tres niveles de gobierno en la promoción del desarrollo; aprovechar y fortalecer la vocación económica de cada región y cada entidad federativa, además de construir la infraestructura básica necesaria para ello; canalizar la inversión pública hacia los programas para el desarrollo económico y social; aumentar la productividad agrícola; atender con programas asistenciales a los grupos sociales más marginados con la finalidad de formar capital humano; respetar y fortalecer los derechos indígenas y las tradiciones culturales de la región; y atraer la participación de los municipios, el empresariado y la sociedad civil en la implementación de los programas y proyectos. En tanto que el Programa Marcha Hacia el Sur privilegia fundamentalmente la atracción y establecimiento de nuevas inversiones en la modalidad de empresas maquiladoras (Gasca y Torres-Torres, 2003). Estos planes y programas, promovidos y gestionados por el gobierno federal e implementados por los gobiernos locales en correspondencia con sus polí- 
ticas públicas, se relacionan con las potencialidades de los territorios del SurSureste y con las ventajas comparativas que ofrecen -biodiversidad, petróleo, gas electricidad, agua y espacios turísticos abundantes; amplia disponibilidad de mano de obra barata; y privilegiada posición geoestratégica para la integración hemisférica y el tránsito de mercancías.

Es a partir de estas ventajas comparativas que tanto las políticas públicas locales como el Plan Puebla-Panamá pretendieron un reposicionamiento del Sur-Sureste mexicano en los sistemas internacionales de producción integrada y en los circuitos comerciales y financieros globales que estimulan los flujos de inversión. Sin embargo, a pesar de las convergencias entre ambos niveles de políticas públicas, la macrorregión Sur-Sureste no es homogénea ni en grados de desarrollo socioeconómico ni en composición cultural; ello en sí mismo, expresado en las múltiples vocaciones y capacidades productivas, en los diferentes grados de integración territorial, y en los diversos problemas públicos y necesidades específicas, resulta un inconveniente al momento de instrumentar las estrategias para el desarrollo regional.

\section{LA DEFINICIÓN Y CONFIGURACIÓN DE LOS PROBLEMAS PÚBLICOS Y LA TOMA DE DECISIONES RELATIVOS AL DESARROLLO REGIONAL}

En la definición de los problemas públicos, en la estructuración de la agenda y prioridades de gobierno, y en la toma de decisiones orientadas a la planeación del proceso de desarrollo, intervienen variados factores, circunstancias, actores y agentes sociales. En otro espacio señalamos $-\mathrm{y}$ en el siguiente aparatado del presente documento ampliaremos- el análisis de la importancia que adquieren los movimientos y las fuerzas sociales opositoras en el diseño e implementación de las políticas públicas (Enríquez, 2006). Tanto estas movilizaciones y la inestabilidad sociopolítica que se propicia como la racionalidad que impone la economía internacional, y el papel que juega el empresariado en la construcción de mercados, son factores y circunstancias que influyen en el diseño de las políticas públicas, múltiples veces inspiradas también por los planteamientos y documentos oficiales que realiza el gobierno federal, los planes y programas transfronterizos y los organismos internacionales (véase diagrama 1).

Uno de los principales actores y agentes sociales que más influye en la definición de los problemas públicos y en las decisiones que adopta el sector público en torno al desarrollo regional es el empresariado privado. En alianza, en coincidencia o en franco rechazo de las políticas públicas que inspiran las acciones gubernamentales, el empresariado, en tanto grupo de presión, posee un importante poder en la modelación de la sociedad a la que se aspira y en la construcción de mercados. 
Aunque proyectos transterritoriales como el Plan Puebla-Panamá se orientan al establecimiento y fortalecimiento de las redes empresariales globales, el empresariado local perteneciente a la macrorregión del Sur-Sureste mexicano y a algunos países centroamericanos (Arróliga, 2002) demanda una mayor participación en la ejecución de los proyectos de infraestructura y en el acceso a la información; la inclusión del sector agropecuario, forestal y pesquero en el Plan Puebla-Panamá; así como un proyecto de integración que implique una unión aduanera, la armonización de aranceles e impuestos, y la reducción de los costos de transporte, energía eléctrica y comunicaciones (Avilés, 2002). En tanto que el apoyo empresarial en materia de desarrollo regional proviene de empresarios como Carlos Slim que impulsa inversiones en el ramo de las telecomunicaciones en Centroamérica, además de empresas como Impulsora del Desarrollo en América Latina cuya intención consiste en financiar proyectos de infraestructura.

En México, gran parte de las propuestas que los empresarios esbozan respecto al proceso de desarrollo giran en torno a la necesidad de imprimir fluidez a las llamadas reformas estructurales; al combate a la inseguridad pública, el contrabando y la piratería; la procuración de certidumbre jurídica para sus actividades e inversiones; el establecimiento de un sistema fiscal que permita aumentar la competitividad de las empresas, la generación de empleos y el fomento de la inversión; el fortalecimiento industrial mediante la generación de condiciones adecuadas (CONCAMIN, 2004a, 2004b, 2004c y 2004d); la inversión en infraestructura (Consejo Coordinador Empresarial, 2003); la mejora regulatoria para impulsar la celeridad de los trámites en las entidades federativas -salvo Veracruz y Quintana Roo, el Sur-Sureste destaca como la región con más baja calidad en su marco regulatorio- y contrarrestar así la pérdida de competitividad, el desaliento a la inversión extranjera directa, la proliferación de las actividades informales, el lento crecimiento económico y la corrupción (Rodarte, 2003).

En el Sur-Sureste, la Confederación Patronal de la República Mexicana con sede en Puebla asume un importante activismo al ser una organización portavoz de las demandas, propuestas y necesidades del empresariado local. Se manifiesta a través de sus boletines de prensa en variados temas como los procesos electorales de la entidad, la inseguridad pública, la reforma fiscal, la reforma laboral, el combate a la corrupción, y la falta de acuerdos políticos. Respecto al desarrollo regional, esta organización empresarial se propone encabezar proyectos que potencien sinergias, en los que empresarios, gobiernos locales, trabajadores, académicos y, en general, las comunidades directamente involucradas, concurran coordinadamente con compromisos concretos, así como promover reformas y políticas públicas para impulsar entornos competitivos al dis- 
minuir el componente exógeno de los costos de las empresas; gestionar la ampliación del número de microrregiones y coordinar -a través de organismos adheridos al Consejo Coordinador Empresarial- el respaldo a las iniciativas empresariales y sociales que surjan en poblados de alta marginación en el estado; identificar y promover conglomerados industriales para el encadenamiento productivo de empresas, en donde el gobierno fortalezca la infraestructura básica indispensable para su desarrollo; y, consolidar y coordinar la actividad de los distintos fondos de desarrollo regional que existen en la entidad (COPARMEXPuebla, 2004). Señalan además la falta de concreción de variados proyectos para el desarrollo regional, incluido el mismo Plan Puebla-Panamá.

\section{LOS PROYECTOS LOCALES AUTOGESTIVOS Y SU INFLUENCIA EN EL DESARROLLO REGIONAL}

En las políticas públicas diseñadas e instrumentadas en México por los distintos niveles de gobierno durante los últimos veinte años, uno de los principales planteamientos en materia de política social y de desarrollo comunitario consiste en propiciar y fomentar el empoderamiento (empowerment) de los actores y agentes sociales que se desenvuelven en las escalas y espacios locales. El logro de la equidad social y el estímulo a la participación autogestiva de los beneficiarios de las políticas sociales se convirtieron en prioridades que marchan a la par con las pretensiones por hacer un uso racional y eficiente del gasto público. Desde las actuales políticas públicas, tanto nacionales como locales, se expresa la necesidad de construir una intensa simbiosis entre las instituciones y recursos del sector público y las manifestaciones y relaciones culturales que gestan capital social en las comunidades. En este sentido, los actores, agentes y organizaciones sociales locales adquieren una relevancia inédita en la construcción de proyectos de desarrollo tanto al amparo de las mismas políticas públicas como los suscitados en el marco de relaciones e interacciones autogestivas que apuestan a posicionamientos, propuestas y estrategias alternativas.

La tendencia general que se advierte en las políticas públicas mexicanas en materia de desarrollo social y humano consiste en promover dicho proceso desde el mismo gobierno a partir del estímulo a la participación de las comunidades, en el entendido de que el aparato de Estado no desarrolla sino que sólo promueve el desarrollo mediante una política social que, privilegiando la corresponsabilidad entre el sector público y la acción solidaria de los actores y agentes sociales y económicos, fomente y consolide las capacidades y aptitudes de los individuos para elevar su calidad de vida. Partiendo de esta premisa, oficialmente al desarrollo social se le concibe como comunitario, autogestivo, fortalecedor de la llamada sociedad civil, y reivindicador y respetuoso de la diversidad cultural y el medio ambiente. 
Como lo analizan y relatan algunos autores (Durston, 2002), la segunda generación de reformas en el ámbito de las políticas sociales que se emprende en América Latina posiciona a la llamada sociedad civil como un contrapeso que puede ser capaz de corregir las fallas e ineficiencias del mercado y de las burocracias centralizadas del sector público en la provisión de los servicios básicos; esto es, la participación de los beneficiarios surgida de la cooperación entre ellos es privilegiada en fases como el diseño, la gestión, ejecución, evaluación y la rendición de cuentas de las políticas públicas orientadas al combate de la pobreza. Mientras la primera generación de reformas consistió en la desincorporación y transferencia -externalización o privatización- de variados servicios públicos a la iniciativa privada, la segunda generación de políticas sociales, tras las inconsistencias e ineficiencias derivadas de las políticas de ajuste y cambio estructural que privilegiaron la estabilización, privatización, desregulación y apertura de las economías nacionales, otorga una mayor importancia a la acción social y a las relaciones de solidaridad y cooperación de las comunidades locales.

El análisis de los actores y agentes sociales locales en las teorías del desarrollo.

Como respuesta a las teorías del desarrollo que privilegiaron el estudio del cambio estructural desde la década de los cuarenta y cincuenta del siglo pasado, surgieron investigaciones que enfatizan la diversidad y el detalle de las formas de vida a partir del análisis de los actores y agentes sociales (Preston, 1996), en especial de aquellos relacionados con los movimientos sociales y la organización autogestiva. Movimientos sociales como el ambientalista y el relacionado con la reivindicación de los derechos y el papel social de la mujer; las protestas y movilizaciones frente a los efectos sociales y ambientales negativos derivados de las políticas de ajuste y cambio estructural de las economías nacionales, así como frente a los organismos internacionales y gobiernos nacionales y locales que las promueven; la creación de organizaciones no gubernamentales (ONG's) para abordar distintos problemas y ámbitos de las sociedades; y la autogestión de las pequeñas comunidades que diseñan proyectos alternativos para el desarrollo endógeno, son todos ellos manifestaciones de la importancia que adquirieron en las últimas décadas diversos actores y agentes sociales involucrados en el mejoramiento de la calidad de vida (para mayores detalles sobre este enfoque teórico obsérvese Enríquez, 2010: cap. 15). Más que un cambio estructural, los supuestos normativos de estas reflexiones se relacionan con la necesidad de emprender intercambios dialógicos orientados al cambio gradual.

El estudio y reconocimiento de las expresiones y relaciones culturales en las escalas locales adquieren creciente importancia en la planeación del proceso de desarrollo al presentarse la tensión y contradicción entre las múltiples 
concepciones e intereses tanto del funcionariado gubernamental como de las comunidades beneficiadas. Las especificidades culturales de los actores y agentes locales resultan cruciales ante la perpetuación de las tendencias que apuntaron en los últimos cincuenta años a que los países subdesarrollados realicen una réplica de las etapas seguidas por los Estados Unidos y las sociedades de Europa Occidental en aras de transitar al ideal de la modernización. Desde éste enfoque, no es que los actores y agentes sociales locales se muestren receptores pasivos; más bien, su imaginación y organización autogestiva los conduce a una asimilación de los criterios oficiales de la planeación que, lejos de ser mecánica, resulta diferenciada y creativa debido en gran medida a que poseen concepciones e interpretaciones propias del mundo y de sus circunstancias y entorno inmediato, así como proyecciones de lo que desean para el cambio de sus sociedades, y estrategias para materializarlo.

Se argumenta que los movimientos sociales, en tanto productores de conocimiento, resisten, adaptan, subvierten el conocimiento dominante de los expertos y tienden a crear el suyo propio; esto es, en los espacios locales se realiza una resistencia o negociación y una reelaboración de las tesis y programas oficiales del desarrollo, de tal manera que las comunidades no se presentan ante el experto con la intención de aceptar mecánicamente sus planteamientos e implementarlos al pie de la letra, más bien, los beneficiarios se los apropian y los reorientan hacia otra racionalidad (Escobar, 2002).

La relevancia del capital social en la formación de proyectos locales para el desarrollo endógeno

Aunque el concepto de capital social cuenta con inconsistencias e imprecisiones en su definición, nos serviremos de él para referirnos a las redes de interacción social que, inspiradas en las expresiones culturales y en la identidad, prevalecen en las comunidades locales que privilegian el diseño e instrumentación de proyectos alternativos y autogestivos para el desarrollo endógeno con base en intensas conductas y relaciones de confianza mutua, solidaridad, reciprocidad interpersonal y asociatividad entre sus miembros que conducen a la cohesión social, la cooperación y el apoyo mutuo en aras de evitar o contener el conflicto y la competencia. El concepto de capital social adquiere relevancia con la difusión de la premisa que sugiere que el proceso económico y sus relaciones se encuentran arraigados e inmersos en entramados socioculturales e institucionales que les brindan legitimación y fluidez en su desempeño.

Cuando las movilizaciones sociales trascienden sus protestas y denuncias esporádicas y fragmentadas, y sus comunidades se organizan en torno a sus valores, prácticas y sistemas culturales, el capital social se gesta, reproduce y cristaliza en los proyectos para el desarrollo local/regional. 
Resulta importante señalar que múltiples proyectos concretos requirieron de la intervención y proyección brindada desde el aparato de Estado; de hecho, las instituciones del sector público pueden constituirse en importantes creadoras e impulsoras de capital social. Más aún, existe una interdependencia entre los esfuerzos dirigidos a reducir la pobreza y la desigualdad y las iniciativas de creación e inversión en capital social, puesto que los primeros -los esfuerzos para reducir la pobreza- influyen en éste último al disminuir la segregación; en tanto que la inversión en capital social al conectar a personas que se encontraban desvinculadas y al contribuir al bienestar socioemocional de las comunidades, tiende a aminorar la desigualdad de ingresos y la pobreza que en cierta medida generan dicha segregación. Con la construcción e incremento del capital social pueden ampliarse las redes de los pobres, mejorar su acceso a los recursos en condiciones favorables, aumentar el valor afectivo atribuido a determinados lugares, intensificar la vinculación y la aproximación al conectar a individuos que poseen diversos orígenes, incrementar las inversiones en bienes públicos y modificar las instituciones en beneficio de los pobres (Robison et al, 2003).

\section{LA ECONOMÍA POPULAR Y LAS CONCEPCIONES Y PROYECTOS ALTERNATIVOS SOBRE EL DESARROLLO REGIONAL EN EL SUR-SURESTE MEXICANO}

Teóricos como John Friedman en su texto Empowerment: The politics of alternative development definen al desarrollo alternativo como la lucha continua por las exigencias morales de la clase pobre desprovista de poder frente a los poderes hegemónicos existentes; además, plantea que toda persona posee el derecho de acceder a adecuadas condiciones materiales de vida y a constituirse en un sujeto políticamente activo en su propia comunidad a partir de elementos como los derechos humanos, los derechos ciudadanos y el florecimiento humano (Friedman, 1992). El mismo Friedman sostiene que en el proceso de empoderamiento de los actores y comunidades en desventaja éstos encuentran en el espacio vital defendible -tanto el hogar como el vecindarioa una de sus principales fuentes de poder social y de sentido de pertenencia.

Las organizaciones locales y los movimientos sociales que impulsan proyectos autogestivos para el desarrollo alternativo realizan un control y una apropiación del territorio, en tanto éste se constituye en una dimensión espacial para la explotación de la naturaleza y para el despliegue de la identidad y de las expresiones culturales de las comunidades. El acervo de conocimientos poseído por los movimientos y organizaciones sociales se gesta a la luz de su constante interacción -tanto local como transnacional- con las instituciones y funcionarios estatales y de organismos internacionales, ONG's, organi- 
zaciones religiosas, comunidades de académicos progresistas, entre otros muchos actores y agentes sociales. Con éste conocimiento se esbozan las concepciones en torno al proceso de desarrollo, al papel del territorio en el proceso económico y a las identidades.

Resulta fundamental la autonomía en la definición de los problemas sociales que padecen las comunidades y en el diseño de los proyectos alternativos para abordarlos. La autonomía radica en la capacidad de las comunidades para definir su propia realidad o para ubicarlas como fuentes de su propio entendimiento o conocimiento, más allá de las tentaciones que puedan tener los planificadores oficiales de transplantar sus planteamientos en la mente de los beneficiarios (Escobar, 2002).

Los proyectos autogestivos de las comunidades locales se gestan a partir de la importancia que adquiere la cultura como factor que propicia identidades en los individuos y que fomenta la integración de éstos a la sociedad. La identidad, en tanto sentido de pertenencia a alguna colectividad, puede convertirse en un incentivo para el aumento de la productividad y la innovación. La cultura se relaciona con el conjunto de valores y prácticas habituales que constituyen y modelan las estructuras sociales y el comportamiento o acción de los individuos, y que impulsan la cooperación y la participación social, y la gestación de tradiciones, costumbres y entramados institucionales facilitadoras de la formación de capital social en las comunidades (para mayores detalles sobre la relevancia de la identidad y las dimensiones simbólico/culturales en las formaciones regionales consúltese Torres-Torres, Delgadillo, Gasca y Enríquez, 2009).

Lo anterior significa que la cultura como mecanismo generador de identidad, integración y cohesión social, así como la misma autoorganización y participación de la comunidad, se posicionan como factores condicionantes para diseñar y adoptar proyectos alternativos de desarrollo regional en los espacios locales.

Con relación a la región Sur-Sureste de México, múltiples fueron las movilizaciones sociales en torno a proyectos de desarrollo regional como el Plan Puebla-Panamá en los últimos años. Entre las fuerzas y movilizaciones sociales opositoras a ésta política pública transnacional que más destacaron se encuentran: 1) los actores, organizaciones o movilizaciones sociales con arraigadas posiciones nacionalistas que denuncian la pérdida de soberanía nacional al instrumentarse proyectos oficiales como el señalado; 2) los actores, organizaciones o movilizaciones sociales localistas que enfatizan los ataques y perjuicios a la identidad cultural de las comunidades indígenas; 3) los actores, organizaciones o movilizaciones sociales que inspirados en la perspectiva del desarrollo sustentable señalan los posibles daños ambientales con la expansión del capital transnacio- 
nal y la construcción de infraestructura y presas, así como la probable proliferación de actividades relacionadas con la biopiratería y la bioprospección en el marco de la adopción del Plan Puebla-Panamá; 4) las organizaciones y movilizaciones que promocionan la defensa de los derechos humanos y reivindican los derechos políticos de las comunidades para participar en la toma de decisiones en materia de políticas públicas; 5) las organizaciones y movilizaciones campesinas y productoras del sector rural que temen el despojo, expropiación y privatización de sus tierras, el desmantelamiento de la agricultura indígena basada en la propiedad social/comunal, y la agudización de la dependencia alimentaria; 6) los académicos y periodistas que con una actitud contestataria conciben y denuncian la dimensión geopolítica, geoeconómica y geoestratégica del Plan Puebla-Panamá; 7) ciertos sectores de la iglesia católica identificados con las causas indígenas e inspirados en la Teología de la Liberación conciben al Plan Puebla-Panamá como una amenaza contra la vida comunitaria y los vínculos culturales; y 8) los actores y organizaciones progresistas que pertenecen o son cercanos a las estructuras de poder político y que ejercieron oposición al proyecto (Enríquez, 2006).

Las demandas de las movilizaciones y organizaciones sociales giraron en torno a su inclusión en el diseño y ejercicio de las políticas públicas relativas al desarrollo regional, así como al acceso a la información detallada sobre las estrategias, programas y proyectos que se desprendan de ellas. Las movilizaciones y fuerzas sociales opositoras que categorizamos anteriormente trascienden al Plan Puebla-Panamá e inscriben su acción colectiva en una perspectiva más amplia relacionada con la oposición y la protesta respecto a los efectos sociales y ambientales negativos derivados de la expansión e integración global del capitalismo en las últimas décadas, así como al posicionamiento desventajoso de las comunidades ante éstos procesos. Además, estas mismas fuerzas sociales opositoras, cuyo radio de acción es el Sur-Sureste mexicano y Centroamérica, a partir de determinados códigos de comunicación comunes se vinculan con otras que gozan de presencia mundial. Son movilizaciones y fuerzas sociales opositoras -y en muchos casos reactivas- que comparten el interés y la preocupación por las problemáticas comunes de las comunidades locales; y multitud de ellas, si bien no surgieron motivadas por la protesta contra el Plan Puebla-Panamá, presentan un traslape de su acción colectiva y sus proyectos con su preocupación por los posibles efectos de dicha política pública.

Durante muchos años, algunas movilizaciones y organizaciones locales, regionales e incluso transnacionales, como resultado de la preocupación y el análisis sobre las problemáticas relativas al desarrollo local o endógeno, participaron en foros y encuentros con otras fuerzas sociales con características similares, y gestaron un acervo de conocimientos que les posibilita la formulación de propuestas alternativas a las políticas públicas. La formulación de 
un modelo alternativo de integración económica que tome en cuenta los problemas nacionales y contribuya a reactivar el mercado interno; la autodeterminación política y autogestión económica de las comunidades; la participación de organizaciones y actores locales en la toma de decisiones y en la materialización de los proyectos; el respeto a la diversidad ecológica, étnica y cultural de sus regiones; el garantizar la seguridad territorial de los pueblos indígenas; la inclusión del componente indígena en los alcances del Plan Puebla-Panamá; basar el potencial de la zona en la integración centroamericana; concebir estrategias de desarrollo comunitario sostenibles que se originen de las experiencias y perspectivas de las comunidades locales (Enríquez Pérez, 2006); son todas ellas propuestas y estrategias alternativas para el desarrollo regional que fueron esbozadas por organizaciones sociales y en eventos internacionales que las congregan.

Como lo señalamos en otro documento (Enríquez, 2006), estas movilizaciones y organizaciones sociales comparten códigos de comunicación comunes y una visión sobre los diferentes problemas de las comunidades y sobre las probables consecuencias negativas derivadas del ejercicio de las estrategias oficiales para el desarrollo regional; además de que en la trayectoria de acción colectiva de algunas de ellas acumularon importantes acervos de conocimientos sobre su realidad, lograron estrechar importantes relaciones de confianza mutua, reciprocidad interpersonal, cooperación, amistad, compadrazgo y solidaridad con las comunidades donde ejercen sus actividades. Como ejemplo de lo anterior destacan algunas movilizaciones de productores rurales que constituyeron numerosas organizaciones para la producción, comercialización y el financiamiento fundamentalmente de actividades agrícolas -como la Coalición de Ejidos de la Costa Grande de Guerrero que construyó empresas sociales, la Coordinadora Estatal de Productores de Café de Oaxaca, la Unión de Comunidades ZapotecasChinantecas, y la Convergencia Regional Campesina "Zanzekan Tinemi" en Guerrero (Flores y Rello, 2002)-; así como expresiones de acción colectiva concretadas en redes de productores, de mujeres campesinas, redes contra la apertura comercial, frentes en defensa de la agricultura, consejos indígenas, entre otros, que crearon entramados de organizaciones que presentan desde una alta cohesión social hasta una expresión coyuntural y efímera así como una dispersión y escasa coordinación de actividades que sólo alcanza a concretarse en manifestaciones de protesta y denuncia que no necesariamente apuntan a la creación de capital social.

Aunque las protestas y movilizaciones sociales en el Sur-Sureste mexicano tienden a ser reactivas, defensivas, esporádicas y efímeras, y no logran constituir formalmente proyectos sociales alternativos, con un trabajo más sólido y permanente destacan el Centro de Investigaciones Económicas y Políticas de Acción Comunitaria (CIEPAC) radicado en San Cristóbal de las Casas y la Red 
Mexicana de Acción Frente al Libre Comercio, organizaciones éstas dotadas de conocimientos e información sistematizados y de capacidad para proponer proyectos alternativos, atentas al aprovechamiento de las tecnologías de la información y capaces de convocar a multitud de actores y fuerzas sociales opositoras. Otras organizaciones como la Alianza Mexicana por la Determinación de los Pueblos (AMAP) y la Unión de Comunidades Indígenas de la Zona Norte del Istmo (UCIZONI) realizan intensas actividades de información, educación a través de talleres y de denuncia sobre los efectos sociales y ambientales negativos derivados de los proyectos oficiales de desarrollo regional (Coalición Internacional para el Hábitat, 2004).

Tanto en las acciones como en las posiciones discursivas de variadas organizaciones sociales predomina una concepción que privilegia estrategias de desarrollo endógeno que parte de reconocer la importancia de la autodeterminación política y de las necesidades y urgencias locales de las comunidades. A manera de tipo ideal argumentamos que uno de los principales proyectos autogestivos y alternativos esbozados por algunas organizaciones sociales es el referido al concepto de economía popular, que consiste en una estrategia económica capaz de privilegiar las necesidades y los mercados nacionales a partir del acceso de los pequeños y medianos productores a éstos, mejorando los rendimientos de sus productos alimenticios y fomentando la pequeña industria, y orientando la infraestructura a la interconexión de las pequeñas comunidades. Todo ello en el marco más amplio del uso y manejo sustentables y alternativos de los cultivos, de la base de recursos naturales y su comercialización; y de la defensa y valoración del capital natural, cultural y patrimonial. Se trata pues, de generar y reproducir el capital social, fomentando la participación comunitaria y la autogestión económica de las comunidades teniendo al campesino y a la mujer como los principales actores y beneficiarios en aras de trascender el actual modelo económico agroexpotador para apostar a una estrategia de desarrollo local/regional fundamentada en la construcción del poder y los mercados desde las bases y comunidades locales (Enríquez Pérez, 2006). Es una concepción del desarrollo regional referida a las localidades y unidades político/administrativas más cercanas; limitada a temas y problemáticas específicas; y orientada al control y uso alternativo del territorio, a la preservación y regeneración de los ecosistemas, y a frenar la migración masiva y el despoblamiento de las comunidades rurales.

A grandes rasgos, la concepción sobre el desarrollo regional emanada de organizaciones sociales y comunidades locales se opone a la ineficiente e inequitativa difusión del bienestar social, así como a las políticas económicas que desde una perspectiva sectorial tendieron a centralizar y concentrar las inversiones públicas y privadas y la infraestructura física y social; estrategias 
éstas que a largo plazo y al no considerar las dimensiones territoriales del desarrollo, propiciaron y profundizaron una dinámica desequilibrada, desarticulada y asimétrica entre las regiones del país. Las movilizaciones y organizaciones sociales delinean y expresan en sus discursos y documentos la posibilidad de formular diversas estrategias de desarrollo local; esto es, más que la construcción de proyectos alternativos de alcance nacional, su acción colectiva se orienta a diseñar y postular una o varias estrategias de desarrollo endógeno que reivindiquen el papel de las comunidades locales y procuren el respeto a su diversidad ecológica y cultural, de tal forma que en no pocos casos, explícita o implícitamente, se tiene como objetivo último insertarse con los menores costos y desventajas a las relaciones económicas prevalecientes en el país. Cuando las movilizaciones y fuerzas sociales opositoras se estancan en una actitud contestataria, reactiva y plagada de excesos en sus planteamientos y acciones, sus alcances y repercusiones en la sociedad resultan mínimos y carentes de capacidad para aprovechar el capital social de las comunidades y para estructurar proyectos de desarrollo alternativo.

\section{CONSIDERACIONES FINALES SOBRE LA INVESTIGACIÓN}

Ante la intensificación de los procesos de globalización, los espacios locales, incluyendo aquellos que experimentaron fases de abandono después de la explotación de sus recursos naturales, adquieren una relevancia inédita en la planeación del desarrollo, en la generación y fortalecimiento de las ventajas comparativas y competitivas, y en la gestación de capital social apropiado para la formulación de proyectos de desarrollo endógeno.

Las nuevas concepciones y estrategias sobre el desarrollo regional expresadas en las políticas públicas diseñadas en las entidades federativas del SurSureste mexicano apuestan al reposicionamiento de dicha macrorregión en el contexto nacional caracterizado por los históricos desequilibrios territoriales, así como en el proceso expansivo de las redes empresariales globales que privilegian las ventajas comparativas y competitivas de los territorios receptores de la inversión privada.

Tal como se observó en el presente documento, son políticas públicas influidas por variadas concepciones relativas al proceso de desarrollo y por variados factores, circunstancias y agentes sociales que pretenden definir los problemas públicos con base en una agenda hegemónica; expresan también diferentes estrategias relativas al rubro del desarrollo regional, sobre todo el orientado al reordenamiento poblacional y a la integración territorial al interior de cada entidad federativa, rebasando con mucho -al menos en el papel-a aquellas concepciones que reducían a la región a una función extractiva de sus recursos natura- 
les, puesto que también son incorporados planteamientos inspirados en el debate teórico sobre el desarrollo sustentable, la equidad de género, el desarrollo humano basado en la creación y expansión de las capacidades, el respeto a la diversidad cultural, el mejoramiento de las instituciones, el empoderamiento de las comunidades locales y la reinvención de la administración pública.

Son políticas públicas que se corresponden y complementan con los instrumentos, estrategias, planes y programas promovidos por el gobierno federal y adoptados por los gobiernos locales. La correspondencia incluso se extiende a proyectos de corte trasnacional como el Plan Puebla-Panamá al presentarse explícitamente la necesidad de colaboración de los gobiernos locales con el gobierno federal y con los gobiernos centroamericanos en materia de construcción de infraestructura vial y productiva.

En general, las concepciones y estrategias sobre el desarrollo regional expresadas en los documentos oficiales de los gobiernos locales se relacionan con la tendencia que apunta a la estandarización de políticas públicas -en el marco de la formación de comunidades epistémicas en espacios globales de toma de decisiones- promovida desde los organismos internacionales y ejecutada desde el gobierno federal, y que responde a las necesidades impuestas por la reestructuración organizacional del capitalismo y a la naturaleza que adquiere hoy en día la construcción de mercados. Dicha tendencia no está exenta, por supuesto, del surgimiento de contradicciones que propician la oposición de las movilizaciones sociales y la emergencia de proyectos de desarrollo autogestivos que haciendo un uso alternativo del territorio esbozan una concepción distinta sobre el desarrollo regional (véase diagrama 1). De ahí la necesidad de analizar, desde una perspectiva integral, a los distintos actores y agentes socioeconómicos y políticos que se disputan el control del territorio y la gestión de los procesos de desarrollo.

En suma, en torno al manejo y apropiación del territorio se polarizan y bifurcan las concepciones, estrategias, objetivos e intereses -el presente documento pretendió caracterizarlos, interpretarlos y compararlos-: por un lado y aunque existen matices y discrepancias en sus planteamientos, los actores y agentes hegemónicos -tanto el funcionariado gubernamental como el empresariado- conciben a los territorios locales -en especial a aquellos que se encuentran en reserva- y a sus recursos naturales como dos instrumentos necesarios para la generación de ventajas comparativas y competitivas que signifiquen un posicionamiento en la integración de la economía mundial; por otro, las organizaciones sociales locales que diseñan proyectos de desarrollo alternativos y autogestivos para la realización de una economía popular, además de concebir al territorio como un factor del proceso productivo propicio para el autoconsumo, lo asumen y valorizan como una representación simbólico/cultural que estructura y arraiga valores, prácticas, tradiciones y costumbres de las comunidades. 
Más aún, cabe destacar que la planeación regional emprendida en México durante los últimos lustros muestra -al momento de ejercer las políticas públicas- una inconexión y/o subordinación con el conjunto de los instrumentos de intervención gubernamental, puesto que ni la política económica ni la política sectorial (agrícola, industrial, etc.) muestran una coordinación y corresponsabilidad con los proyectos regionales que, por cierto, no logran articular el mercado interno ni atemperar la erosión que la expansión e integración global del capitalismo imprime sobre la economía nacional. Esta falta de coordinación -a la par de las concepciones sobre el desarrollo que subyacen en la totalidad de las políticas públicas nacionales- son parte de los factores que explican el fracaso e inviabilidad de políticas transfronterizas como el Plan Puebla-Panamá que postulan a la economía mundial como la nueva racionalidad; de ahí que resulte preciso reivindicar -de cara a la incertidumbre y volatilidad que impone la crisis financiera global y sus secuelas sobre el aparato productivo- la (re)construcción de un proyecto de nación con base en la revitalización de la región y los espacios locales, en tanto ámbitos que condensan la identidad cultural y las sinergias positivas necesarias para reinventar un país.

\section{BIBLIOGRAFÍA}

ARRÓLIGA, L. (2002). "Empresarios ambientalistas discrepan sobre el PPP", Nicaragua, Confidencial, Semanario de información y análisis, año 6, núm. 286, del 21 al 27 de abril.

AVILÉS, R. (2002). "FUSADES: hay que hablar de una verdadera integración", El Salvador, en La Prensa, www.laprensa.com.sv

BCIE-BID-CEPAL (2001). Plan Puebla-Panamá. Iniciativas Mesoamericanas y proyectos, El Salvador, Grupo Técnico Interinstitucional para el Plan Puebla-Panamá, Banco Centroamericano de Integración Económica (BCIE), BID, CEPAL e INCAE.

BUSTAMANTE, C. et al (2004). "Política económica y desarrollo regional en México: impacto y perspectiva", ponencia presentada XX Seminario de Economía Mexicana titulado La economía mexicana y su intercambio externo: situación actual y perspectivas, Instituto de Investigaciones Económicas (IIEc) de la UNAM, 23 al 26 de agosto.

COALICIÓN INTERNACIONAL PARA EL HÁBITAT (2004). Plan Puebla Panama.com, México DF: Coalición Internacional para el Hábitat Oficina para América Latina (HIC-AL).

CONFEDERACIÓN PATRONAL DE LA REPÚBLICA MEXICANA-PUEBLA (2004). "25 Propuestas para Mejorar la Competitividad y el Bienestar en el Estado de Puebla", Puebla, 18 de octubre, www.coparmexpuebla.org.mx

CONCAMIN (2004a). "Plantea la directiva de CONCAMIN nuevas estrategias en competitividad", Boletín de Prensa, 21 de mayo, www.concamin.org.mx 
(2004b). "La mejora regulatoria como factor de competitividad y crecimiento en México", Boletín de Prensa, 26 de mayo, www.concamin.org.mx

(2004c). "Necesario evitar que lo político contamine el tema económico: León Halkin Bider", Boletín de Prensa, 31 de mayo, www.concamin.org.mx (2004d). "El sector industrial hace un llamado al Ejecutivo y al Legislativo para construir una alianza en pro del crecimiento", Boletín de Prensa, 19 de agosto, www.concamin.org.mx

CONSEJO COORDINADOR EMPRESARIAL (2003). Discurso pronunciado por el Ingeniero Héctor Rangel Domene, Preidente del Consejo Coordinador Empresarial en el evento de mejora regulatoria. Los Pinos, 17 de junio, www.cce.org.mx

DELGADILLO, J., TORRES-TORRES, F. Y GASCA, J. (2001). El desarrollo regional de México en el vértice de dos milenios. México DF: Instituto de Investigaciones Económicas de la UNAM y Miguel Ángel Porrúa.

DURSTON, J. (2002). El capital social campesino en la gestión del desarrollo rural. Díadas, equipos, puentes y escaleras. Santiago de Chile: Naciones Unidas-CEPAL.

ENRÍQUEZ, I. (2006). "La respuesta social mesoamericana y los esfuerzos por articular estrategias alternativas de desarrollo", en: F. TORRES-TORRES Y J. GASCA (Coords.), Los espacios de reserva en la expansión global del capital. El sur-sureste mexicano de cara al Plan Puebla-Panamá. México DF: Instituto de Investigaciones Económicas (IIEc), Facultad de Economía e Instituto de Geografía de la UNAM y Plaza y Valdés Editores, pp. 297-319.

(2010). La construcción social de las teorías del desarrollo: un estudio histórico/crítico para incidir en el diseño de las políticas públicas. México DF: Editorial Miguel Ángel Porrúa y H. Cámara de Diputados.

ESCOBAR, A. (2002). "Globalización, desarrollo y modernidad", en la revista Corporación región. Medellín: Editorial Planeación, participación y desarrollo, 9-32.

FLORES, M. Y RELLO, F. (2002). Capital social rural: Experiencias de México y Centroamérica. México DF: Facultad de Economía de la UNAM, CEPAL-Sede México y Plaza Valdés Editores.

FRIEDMAN, J. (1992). Empowerment. The politics of alternative development. Oxford: Blackwell Publisher.

GASCA, J Y TORRES-TORRES, F. (2003). "El Plan Puebla-Panamá y la asimilación extensa del Sur-Sureste de México en tiempos de la globalización", en memoria del XII Seminario de Economía Urbana y Regional 2002 titulado Teorías y proyectos de desarrollo urbano regional en México. México DF: IIEc, PUEC y CRIM de la UNAM y El Colegio Mexiquense, A. C., Primera Edición en CD-ROM.

GOBIERNO DEL ESTADO DE CAMPECHE (2004). Plan Estatal de Desarrollo 20032009, México, Gobierno Constitucional del estado de Campeche, Colección Campeche, núm. 1.

GOBIERNO DEL ESTADO DE CHIAPAS (2001). Plan de Desarrollo Chiapas 2001-2006, México, Secretaría de Planeación del Gobierno Constitucional del estado de Chiapas, Primera Edición. 
GOBIERNO DEL ESTADO DE GUERRERO (1999). Plan Estatal de Desarrollo 1999-2005, consultado en junio de 2004, www.guerrero.gob.mx

GOBIERNO DEL ESTADO DE OAXACA (1999). Plan Estatal de Desarrollo 1998-2004, consultado en junio de 2004, www.oaxaca.gob.mx

GOBIERNO DEL ESTADO DE PUEBLA (1999). Plan Estatal de Desarrollo 1999-2005, consultado en junio de 2004, www.puebla.gob.mx

GOBIERNO DEL ESTADO DE QUINTANA ROO (1999). Plan Básico de Gobierno 1999-2005, consultado en junio de 2004, www.quintanaroo.gob.mx

GOBIERNO DEL ESTADO DE TABASCO (2002), Plan Estatal de Desarrollo 2002-2006, consultado en junio de 2004, www.tabasco.gob.mx

GOBIERNO DEL ESTADO DE VERACRUZ (1999). Plan Veracruzano de Desarrollo 1999-2004, consultado en junio de 2004, www.veracruz.gob.mx

GOBIERNO DEL ESTADO DE YUCATÁN (2001). Plan Estatal de Desarrollo Yucatán 2001-2007, 153 pp., consultado en junio de 2004, www.yucatan.gob.mx

PRESIDENCIA DE LA REPÚBLICA (2001). Plan Puebla-Panamá (Documento Base. Capitulo México), Presidencia de la República, presentado el 12 de marzo.

PRESTON, P.W. (1996). Development theory, an introduction. Oxford: Blackwell Publishers. ROBISON ET AL (2003). "El capital social y la reducción de la pobreza: hacia un paradigma maduro", en: ATRIA, R. Et al (Comp.). Capital social y reducción de la pobreza en América Latina y el Caribe: en busca de un nuevo paradigma. Santiago de Chile: Naciones Unidas-CEPAL y Universidad del Estado de Michigan, 51-113.

RODARTE, M. (2003). Calidad del marco regulatorio en las entidades federativas. Estudio comparativo 2002. México DF: Centro de Estudios Económicos del Sector Privado (CEESP), www.cce.org.mx/ceesp

TORRES-TORRES, F; GASCA, J.; DELGADILLO, J. y ENRÍQUEZ, I. (2009). Formaciones regionales comparadas. Los casos de España, Italia y México. México DF: IIEcUNAM y El Colegio de Tlaxcala. 